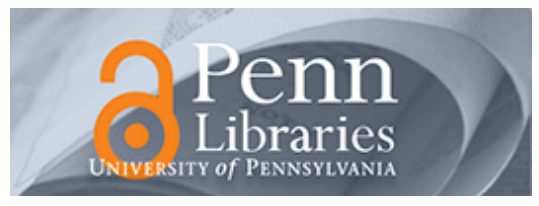

University of Pennsylvania

ScholarlyCommons

Finance Papers

Wharton Faculty Research

2-1991

\title{
Was there a "Peso Problem" in the U.S. Term Structure of Interest \\ Rates: 1979-1982?
}

Karen K. Lewis

University of Pennsylvania

Follow this and additional works at: https://repository.upenn.edu/fnce_papers

Part of the Finance and Financial Management Commons

\section{Recommended Citation}

Lewis, K. K. (1991). Was there a "Peso Problem" in the U.S. Term Structure of Interest Rates: 1979-1982?.

International Economic Review, 32 (1), 159-173. http://dx.doi.org/10.2307/2526938

This paper is posted at ScholarlyCommons. https://repository.upenn.edu/fnce_papers/171

For more information, please contact repository@pobox.upenn.edu. 


\title{
Was there a "Peso Problem" in the U.S. Term Structure of Interest Rates: 1979-1982?
}

\author{
Abstract \\ During the period following October 1979 through 1982, the U.S. Federal Reserve allowed interest rates to \\ fluctuate widely, in contrast to its previous policy of targeting these rates in the 1970 . The policy was \\ abandoned in 1982 in favor of an operating procedure that reduced the variation in interest rates. This \\ paper implements an estimation method to identify from the term structure of Eurodollar returns the \\ market's beliefs that the Fed may revert to interest rate targeting. The model is not rejected and gives \\ plausible estimates of the probability of a switch in monetary regimes.

\section{Disciplines} \\ Finance and Financial Management
}


NBER WORKING PAPER SERIES

WAS THERE A "PESO PROBLEM" IN THE U.S. TERM STRUCTURE OF INTEREST RATES:

1979-1982?

Karen K. Lewis

Working Paper No. 3282

\author{
NATIONAL BUREAU OF ECONOMIC RESEARCH \\ 1050 Massachusetts Avenue \\ Cambridge, MA 02138 \\ March 1990
}

I am grateful to two anonymous referees, Bill Greene, Jim Hamilton, and seminar participants at Columbia University and the NBER Summer Institute for useful comments and suggestions, and to the Glucksman Institute and the Salomon Brothers Center for Financial Studies for research support. This paper is part of NBER's research program in International Studies. Any opinions expressed are those of the author and not those of the National Bureau of Economic Research. 
NBER Working Paper \#3282

March 1990

WAS THERE A "PESO PROBLEM" IN THE U.S. TERM STRUCTURE OF INTEREST RATES:

1979-1982?

\section{ABSTRACT}

During the period following October 1979 through 1982, the U.S. Federal Reserve allowed interest rates to fluctuate widely, in contrast to its previous policy of targeting these rates in the 1970 . The policy was abandoned in 1982 in favor of an operating procedure that reduced the variation in interest rates. This paper implements an estimation method to identify from the term structure of Eurodollar returns the market's beliefs that the Fed may revert to interest rate targeting. The model is not rejected and gives plausible estimates of the probability of a switch in monetary regimes.

Karen K. Lewis

New York University and NBER

1050 Massachusetts Avenue

Cambridge, MA 02138 
In October 1979, the Federal Reserve announced a new operating procedure for conducting monetary policy. Following this announcement, the behavior of interest rates changed dramatically. In particular, both the level and the variance of short term interest rates increased significantly. For example, from an average level of 7.68 and varfance of 5.78 on the annualized one-month Eurodollar rate during the mid-1970s, its mean and variance rose to 15.3 and 10.58, respectively, during the period when the Fed targeted non-borrowed reserves (NBR) from October 1979 to September 1982. The behavior of the term structure of U.S. Interest rates also shifted. While the spread between three-month and one-month Eurodollar deposits rates were on average .22 percentage points from mid-1974 to September 1979, this spread became negative during the NBR targeting period. The ex post returns from holding these longer term three-month deposit rates relative to rolling over one-month deposit rates also fell, particularly during the continual rise in short term interest rates into 1981 .

As the Fed allowed wide fluctuations in interest rates following the October 1979 change in policy, market observers appeared to speculate (evidenced by newspaper and other media accounts) that this policy could not be sustained. The market seemed to believe the Fed would be forced by political factors to revert back to some form of interest rate targeting, a shift in policy that would induce a discrete change in process of interest rates. In fact, this change in policy did occur in the latter part of 1982.

This paper addresses whether market anticipation of a switch in monetary policy course systematically affected the ex post returns on longer term relative to short-term U.S. Interest rates. As first pointed out by Rogoff (1979), when the market expects a discrete change in policy that does not materialize for some time, these expectations will induce forecast errors that in small samples are systematically mistaken ex post, called the "peso 
problem." 1 In the case of the 1979 to 1982 period, a persistent belief that the Fed would not allow interest rates to continue to increase would have lowered the ex post returns on longer term relative to short term interest rates. Therefore, a "peso problem" in the U.S. term structure of interest rates may help explain why these returns were lower during the 1979 to 1982 period.

The effects of discrete changes in economic variables have been the subject of studies in many different areas of economics. Further, the potential importance of discrete state processes in various empirical applications has been noted at least since the work of Goldfeld and Quandt (1973). Using a nonlinear filter with antecedents in works following this tradition, Hamilton $(1988,1989)$ has studied a number of economic time series, including the term structure of interest rates. ${ }^{2}$

In contrast to these and similar studies, the analysis in this paper differs in several respects that focus upon the "peso problem" during the NBR targeting period. First, the presence of a "peso problem" in long-term rates would appear as the anticipation of a future change in policy even though current Fed policy may be known with certainty by the market. Therefore, this feature of market behavior is incorporated into estimation of the "peso problem" effect. ${ }^{3}$ Second, since the period of NBR targeting was quite short, relatively high frequency data must be used to analyze any behavior specific to the period. For this reason, weekly frequency Eurodollar rates are used to

$1_{\text {See also Krasker }}(1980)$ and Lizondo (1983).

${ }^{2}$ This filter has roots in the works of Neftci (1982) and Cosslett and Lee (1985). See Hamilton (1989).

${ }^{3}$ By contrast, with the filter used in Hamilton $(1988,1989$ ) the market does not know the current regime, but infers it from observing the current economic variable. Consistent with the approach taken in this paper, however, his estimates indicate that the market knew with virtual certainty the current process during the NBR targeting period. 
study the behavior of three-month relative to one-month deposits. Third, since the structure of the market's beliefs are not known to the econometrician, various forms of the probabilities assessed by the market are examined empirically. ${ }^{4}$ Assuming first that these probabilities are constant, a Markov process appears consistent with the data. Next, allowing the probabilities to vary over time, the implied anticipations of a policy change over the period of NBR targeting seems fairly plausible. Overall, the approach developed in the paper is quite general and can be applied to other situations where the current state is known but future discrete states are uncertain.

The economic behavior of this approach is developed in the context of the term structure of interest rates in Section 2 below. Section 3 discusses the empirical methodology, while Section 4 describes the data. Section 5 sumarizes specification tests and documents the instability of U.S. interest rates over the NBR period. Sections 6 and 7 report the empirical evidence for the "peso problem" when the probability of a switch in Fed policy is assumed to be constant and time-varying, respectively. Concluding remarks follow.

\section{The "Peso Problem" and Excess Returns on Long Bonds}

For the purpose of understanding how a 'peso problem' affects the returns on longer-term relative to short-term interest rates, consider a strategy of investing in a longer maturity bond relative to rolling over the investment in

${ }^{4}$ Hamilton (1989) imposes a Markov process on the discrete state random variable and uses the filcered likelihood to estimate this probability. In the analysis in this paper, whether the market belleved that the discrete state process followed a Markov process will be a particular case to be examined empirically. 
a shorter maturity bond for successive periods. ${ }^{5}$ Specifically, in this paper we will be investigating the returns on three-month deposits relative to rolling over one-month deposits. Assuming that the strategy can be linearized, this implies the standard term structure relationship at time between the three-month rate, defined as $R_{t}$, and the one-month rate, $r_{t}$, according to:

$$
R_{t}=P_{t}+E_{t}\left\{(1 / 3) \underset{s=0}{\Sigma} r_{t+s k}\right\}
$$

where $P_{t}$ is the risk premium at time $t$ associated with holding a three-month relative to rolling over a one-month bond and where $E_{t}$ is the expectations operator conditional on information available at time t. In eq. (2.1), we have allowed the sampling of observations to be finer than a month: i.e., $k$ equals the number of observations of the returns series within a month. In the application below, we will use weekly frequency data to increase the number of observations over the relatively short NBR targeting period, so that $k$ will be about 4 .

Suppose now that market participants believe the interest rate process may change for reasons not fully captured by interest rates, such as political factors. For example, part of the market's belief that the Federal Reserve could not sustain its policy stance appeared to arise from the political unpopularity of the high level of interest rates in conjunction with the recession induced by fiscal cutbacks. When bond traders believe that two distinct interest rate processes are possible in the future, they condition


survey by Shiller and McCullough (1987). Since the present study uses Eurocurrency deposit data, it is related to the literature on the term structure of the forward market in foreign exchange, as in Hakkio (1981a, 1981b). Froot (1988) uses survey data to investigate the expectations hypothesis of the term structure of interest rates and finds systematic forecast errors for short term rates, consistent with the "peso problem" effects discussed in this paper. 
expectations upon each process when forming predictions of future interest rates. They then weight each conditional forecast by their assessed probability of the switch in policy. Therefore, the expected one-month and two-month ahead interest rates can be written:

$$
E_{t} r_{t+k}=\pi_{1} E_{t} r_{t+k, 2}+\left(1-\pi_{1}\right) E_{t} r_{t+k, 1}
$$

$$
E_{t} r_{t+2 k}-\pi_{2} E_{t} r_{t+2 k, 2}+\left(1-\pi_{2}\right) E_{t} r_{t+2 k, 1}
$$

where $E_{t} r_{t+s k, j}$ is the expectation of the interest rate $s$ months ahead conditional upon the future interest rate following process $j$, and $\pi_{i}$ is the market's assessed probability that the interest rate $i$ months ahead will follow process 2. Thus, eq. (2.2) says that market participants use two different interest rate processes to condition expectations. For example, during the NBR targeting period, the market likely believed that the Fed would have to revert to previous policy, implying interest rate behavior similar to the pre-NBR period. Defining $x_{t}$ as a set of variables that are predetermined at time $t$ and letting the subscript $j=1,2$ denote the interest rate regime, these two processes can be summarized by the following equations: 6

$$
r_{t+k, j}-\beta_{i j} x_{t}+\eta_{t, j}^{1}
$$

$$
r_{t+2 k, j}=\beta_{2 j}^{\prime} x_{t}+\eta_{t, j}^{2} \text { for } j-1,2 \text {. }
$$

Since the market's forecast of the interest rate one-month and two-months ahead is rational conditional upon the process $j$, the conditional forecast errors, $\eta_{t, j}$, are orthogonal to time $t$ information.

${ }^{6}$ Implicitly, this relationship assumes that, in the event of a switch from $t$ to $t+k$ or $t$ to $t+2 k$, it occurs in the beginning of this interval. 
Given these beliefs, we may now consider the 'peso problem' in the term structure. Suppose that ex post the econometrician observes long and short rates during a period (such as the NBR period) when interest rates followed a particular process $j$, indicated by $R_{t, j}$ and $r_{t, j}$. Substituting eqs. (2.2) into (2.1) and rearranging gives the following equation:

$$
\begin{aligned}
R_{t, 1}= & p_{t}+(1 / 3)\left[r_{t}+E_{t} r_{t+k, 1}+E_{t} r_{t+2 k, 1}\right] \\
& +\pi_{1}(1 / 3)\left[E_{t} r_{t+k, 2}-E_{t} r_{t+k, 1}\right] \\
& +\pi_{2}(1 / 3)\left[E_{t} r_{t+2 k, 2}-E_{t} r_{t+2 k, 1}\right]
\end{aligned}
$$

Equation (2.4) shows the right-hand side decomposed into four terms. The first term, $P_{t}$, is the risk premium on longer maturity bonds. The second component is the term structure relationship under process 1 . These first two terms arise in the standard term structure relationship with no switches in policy. The third and fourth components correspond to the "peso problem" for one-month ahead and two-month ahead interest rate forecasts, respectively. As long as interest rates follow regime 1 ex post, the probability of a shift in the interest rate process to regime 2 will induce a bias in forecasts implicit in long rates. Of course, with sufficient observations on the interest rates that include regime 2 , this bias would disappear.

Within this framework, we may consider the likely effects of this peso problem on the relationship between long and short rates during the NBR targeting period. If the market believed that interest rates would be lower under regime 2 (interest rate targeting) than under regime 1 (NBR targeting), then the "peso problem" terms, $E_{t} r_{t+s k, 2}-E_{t} r_{t+s k, 1}$, would on-average be negative over the period. Therefore, this "peso problem" effect is consistent with the systematic decline in the excess return on long bonds relative to short bonds noted in the introduction. 


\section{Emptrical Methodology}

As eqn. (2.4) illustrates, estimating the "peso problem" effect of the returns on long bonds relative to rolling over short bonds requires an estimate of the market's expectation of the future interest rates conditional upon each regime. Since the econometrician does not know all of the variables that agents use to form expectations, the expected future interest rates are not observed directly. However, estimates of the future interest rates may be obtained using a subset, $z$, of the Information set according to:

$$
E_{t} r_{t+k, j}-\alpha_{j}^{\prime} z_{t}+u_{t, j}
$$

$$
E_{t} r_{t+2 k, j}-\gamma_{j}^{\prime} z_{t}+w_{t, j}
$$

where $u_{t, j}$ and $w_{t, j}$ are the errors in measuring the expected interest rates conditional upon regime $f$ at one-month ahead and two-months ahead, respectively.

In cases when ex post the econometrician reasonably recognizes the regime that was followed (as seems reasonable for the NBR targeting period), this information can be used to identify the expectations conditional upon each regime. Specifically, during each regime, the projection of interest rates on a subset of information varlables, $Z$, provide estimates of the relationship according to,

$$
r_{t+k, j}=\alpha_{j} z_{t}+e_{t}^{1}
$$

$$
r_{t+2 k, j}=\gamma_{j}^{\prime} z_{t}+e_{t}^{2} \text { for } j=1,2
$$

where $e_{t}^{1}=u_{t, j}+\eta_{t}^{1}$, the composite error on one-month ahead forecasts, and $e_{t}^{2}=w_{t, j}+\eta_{t}^{2}$, the composite error on two-month ahead forecasts. By rational expectations, $\eta$ are orthogonal to all information at time $t$, including $z_{t}$. 
Since the frequency of the data is higher than the forecasting interval (that is, $s k>1, s=1,2)$, these forecast errors will follow an MA(sk-1) process. In addition, the errors in measuring expectations, $u_{\tau}$ and $w_{\tau}$, are orthogonal to $z_{\tau}$ by construction, although in general they may be serially correlated. Therefore, one indication of how well the subset $z_{t}$ measures expectations is to test whether the composite errors, $e_{t}{ }^{s}$, follow an MA(sk-1) process. This test will be reported below.

Substituting ( 3.2 ) into (2.4), subtracting the ex post short rates from each side and rearranging, we obtain the estimation equation,

$$
\begin{aligned}
& R_{t, 1}-(1 / 3)\left[r_{t, 1}+r_{t+k, 1}+r_{t+2 k, 1}\right]=p_{t}+\pi_{1}(1 / 3)\left(\alpha_{2}-\alpha_{1}\right) \cdot z_{t} \\
& +\pi_{2}(1 / 3)\left(\gamma_{2}-\gamma_{1}\right) \cdot z_{t}-(1 / 3)\left[\eta_{t, 1}^{1}+\eta_{t, 1}^{2}\right] \\
& +\pi_{1}(1 / 3)\left[u_{t, 2}-u_{t, 1}\right]+\pi_{2}(1 / 3)\left[w_{t, 2}-w_{t, 1}\right] .
\end{aligned}
$$

If the probabilities of a switch are constant over time, then we may estimate these probabilities as parameters through the joint system of equations ( 3.3 ) and (3.2). This system identifies the expectation effects through (3.2), and identifies the probabilities through the term structure relationship in ( 3.3 ). As noted above, the ex post forecast errors, $\eta$, are orthogonal to all current information while the measurement errors are orthogonal to $z_{t}$ by construction. ${ }^{8}$ Thus, we can estimate this non-linear system while correcting for the moving average error terms induced by over-lapping forecast errors.

Several interesting cases may be investigated within this framework. As a natural first case, we may assume that the probabilities are constant over

\section{${ }^{7}$ See Hansen and Hodrick (1980).}

${ }^{8}$ Technically, the error in measuring expectations conditional upon regime 2 are constructed during the period when the regime 2 process is being followed. Therefore, in order for this measurement error to be orthogonal to $Z$ when interest rates follow regime 1 , we require that the joint marginal distribution of $Z$ and the omitted variables in the information set be stable over the change in Fed policy. 
time. By estimating the $\pi_{i}$ terms directly, we can test for the presence of a "peso problem" both individually in any period, $\pi_{i}-0 ;$ and jointly over boch periods in the term structure: $\pi_{1}-\pi_{2}-0$. In addition, we can test whether this probability was the same over both periods through $\pi_{1}-\pi_{2}=\pi$. Intuitively, we would anticlpate that $\pi_{2}>\pi_{1}$ since as the time horizon increases, it would seem more likely that a switch would occur. Another interesting case is that $\pi$ may vary over time as a function of the information variables, as will be considered in section 7 below.

\section{Data Description}

In order to increase the efficiency of estimation over the three month period of NBR targeting, the empirical analysis below uses weekly frequency data. However, the use of high frequency data restricts the available set of information variables in $z_{t}$. To be consistent with the framework above, we require variables that are (a) observed weekly, (b) are correlated with U.S. interest rates, and yet (c) did not shift with the change in Fed policy. The first and second requirements indicate that the variables should be financial, while the third requirement excludes most U.S. financial variables. For this reason, foreign interest rates were chosen as information variables. ${ }^{9}$ In order to align the U.S. interest rate series with the foreign interest rate series, all interest rates were taken from the same Eurocurrency market. Specifically, the data are Friday observations (noon in New York, EST) of 3month and 1-month Eurodollar deposit rate, and of the Eurocurrency rates for the Deutschemark, the Dutch guilder, and the British pound. 10 Since these

9 In addition, Mankiw (1986) finds that U.S. incerest rates are correlated with foreign interest rates.

${ }^{10}$ The data set also contained series for the Swiss franc, the French franc, and the Japanese yen. However, the one-month rates for the French franc and the Japanese yen did not begin until 1979. And, due to capital controls in the early 
data are observed at the end of the week but the one-month deposit rates are for 30 day holding periods, we require an approximation to the excess return on the left-hand side of (3.3). In particular, $k$ is set equal to 4 so that the future one-month deposit is aligned with the 28 day ahead rate. ${ }^{11}$

5. Shifts in the Process of Interest Rates

As is well known, the behavior of U.S. interest rates changed dramatically during the period of non-borrowed reserves targeting. However, in order to investigate the 'peso problem' model using the projection equations in (3.2), we must first establish that the joint behavior of U.S. interest rates and the information variables, $Z$, shifted significantly and consider some preliminary evidence on the behavior of these projections.

Table 1 reports sumary statistics on projection equations for three subperiods before, during, and after the NBR targeting period, respectively These projections are also conducted usirg two different forms of the lefthand side variables. The first form of the left-hand side variable, reported under Panel $\mathrm{A}$, is the monthly differerce in the U.S. (one-month) interest rate series. This form was investigated since Box-Jenkins time-series identification suggested that interest rates before and after the NBR targeting period contained unit roots. However, using this same analysis interest rates during the NBR targeting period appeared to be stationary. The second form, reported under Panel B, takes the future level of interest rates as the left-hand side variable.

10 (...continued) floating rate period, the Swiss franc had periods of negative Eurodeposit rates. These problems therefore excluded these series as candidate information variables.

${ }^{11}$ Experimentation with variations on this series did not seem to alter the general results, however. 
In order to check the robustness of the results to different variables included in the information variables, $z$, three different sets were considered labeled A to $C$ from largest to smallest. Set $A$ is comprised of a constant, the spreads between one-month Eurocurrency rates and the Eurodollar rate, and the spreads between three-month and one-month Eurocurrency rates for the Deutschemark, the British pound, and the Dutch guilder. Set $B$ excludes the Dutch rates from this information varlable set, while Set $C$ excludes the spreads between three-month and one-month rates.

Panel A reports the projection equations for the change in the interest rates for one and two months ahead. For the one-month ahead equations, the hypothesis that the coefficients were jointly zero was rejected at the 958 confidence level for both the first and second subperiods, but not the third subperiod. For the two-month ahead projections (under subheading 2), this hypothesis was not rejected except for the NBR targeting period.

As illustrated by eq. (3.2), when the estimation equations pick up most of the forecastability of interest rates, the residuals in the one-month ahead projections should contain a moving average component of order 3 arising from the forecast error, $\eta$. Therefore, as a check on the model, the table also reports the marginal significance levels of the test described in Cumby and Huizinga (1988a). Specifically, these marginal significance levels are for the hypothesis that the autocorrelations of the residuals are jointly zero after lag 3 (through lag 9). For the early period prior to NBR targeting, this hypothesis is rejected at the 958 confidence level for the one-month ahead projections and for the two-month ahead projections using information variables set $C$. 
Panel A also reports a Wald test that the projection coefficients were the same during the NBR targeting period as before and after, ${ }^{12}$ For all three instrument sets, the hypothesis of constant coefficients for both the onemonth ahead and the two-month ahead projections were rejected with marginal significance levels less than 18 . Panel $B$ reports these tests using the level of one-month and two-month ahead rates. In this case, the hypothesis that the coefficients are jointly equal to zero is strongly rejected in all cases with marginal significance levels less than .1\%. Furthermore, as indicated by the test for autocorrelation beyond three lags, the regressors appear to pick up much of the predictable serial correlation. Except for the one-month ahead projection during the NBR period using Set $C$ and the two-month ahead projection during the later period using set $B$, the test statistics have marginal significance levels above 108 . The Wald cest that the coefficients during the NBR targeting period are the same as the other periods is strongly rejected for all three instrument sets and for both one- and two-month ahead rates.

Thus, both versions of the projections appear consistent with the requirements for estimating the system of equations (3.2) and (3.3) and both were used to estimate the model. While the qualitative results were similar in both cases, the parameter estimates using the change form of interest rates were very imprecisely estimated. ${ }^{13}$ Furthermore, since the time series identification analysis suggested that interest rates were stationary during the (NBR) period of interest, the results to be reported below use the interest rate level projections to prevent over-differencing.

12 Similar results obtained when the latter period was excluded. Newey and West (1987b) show that the Wald test is asymptotically equivalent to the Lagrange multiplier and the likelihood ratio test in method of moments estimation.

${ }^{13}$ Some of these results are reported in Lewis (1988). 


\section{The "Peso Problem" With Constant Probabilities}

In order to estimate the "peso problem" relationship in eqn. (3.3), we must specify the behavior of the term premium, $p_{t}$. Three different specifications of this premium gave virtually identical estimates of the "peso problem" effect. Therefore, only the results assuming a constant term premium are reported, since it was the simplest of these specifications. 14

The term structure equation in (3.3) was estimated jointly with the projection equations (3.2) for the one-month and two-month ahead Eurodollar rates. The NBR period identified the coefficients for Regime $1\left(\alpha_{i l}, \gamma_{i l}\right)$, while observations for the periods before and after this period were used to estimate the Regime 2 parameters $\left(\alpha_{12}, \gamma_{12}\right) .15$ The five equation non-iinear model was estimated using Hansen's (1982) method of moments, correcting the variance-covariance matrix for conditional heteroscedasticity, an MA(3) process in the interest rate equations and an MA(8) process in the term structure equation (3.2) with the estimator described in Newey and west (1987a). 16

Table 2 reports the parameter estimates for the probabilities and the term premium. ${ }^{17}$ As the table shows, the estimates of the probabilities are

${ }^{14}$ The three versions were: (a) the premium is a linear function of information variables, (b) no premium, (c) constant premium. See Lewis (1988).

15 A Wald test of the hypothesis that the coefficients before and after the NBR period were the same could not be rejected. However, estimates of the model omiting the later sample gave very similar parameter results.

${ }^{16}$ The MA(8) process is implied by overlapping forecast errors in eqn. (3.3) under rational expectations (Hansen and Hodrick (1980)), while the MA(3) process was tested in Table 1 and discussed in section 5. The system was estimated using the computer program described in Cumby and Huizinga (1988b). In order to minimize the effects upon the standard errors on the 'peso problem' estimates due to potential non-stationarity in interest rates during the pre- and postNBR periods, the information matrix was restricted to be block diagonal between this block of parameters and that of the other parameters.

17 The other parameter estimates are available upon request from the author. 
very imprecisely estimated. The one-month ahead probabilities, $\pi_{1}$, are never significantly different than zero and have negative point estimates for all three information sets. The two-month ahead probabilities of a change in policy are significantly different than zero for Sets $A$ and $B$, but not for $S e$ C. Furthermore, these point estimates are greater than one for all three information sets. Estimates of the term premium are not significanty different than zero and have negative point estimates for two of the three instrument sets:

As discussed above, we can consider whether there was a "peso problem" across the two periods by testing the hypothesis that the two probabilities were jointly zero. For this purpose, the marginal significance levels of a Wald test of this hypothesis are also reported in the table and are all less than . $1 \%$. To address whether the probabilities were increasing over time, the MSL are also reported for the hypothesis that the probabilities are the same. However, only the larger instrument set A can reject this hypothesis at standard significance levels. Finally, the last row of the table reports the marginal significance levels for the test of over-identifying restrictions. These restrictions are not refected for any of the sets of information variables.

The estimated results in Table 2 treat the one-month and two-month ahead probabilities of a shift in Fed policy as independent probabilities. Therefore, precision of estimation may be improved by incorporating information about the evolution of these probabilities across the term structure. A simple and convenient way to parameterize this evolution is to assume that the market's assessed probabilities follow a Markov process. Market participants are assumed to believe that, if a change in interest rate policy occurs within the next month, the Fed will not shift back again to NBR 
targeting two months from now. This assumption implies that transition matrix to the Markov process can written as:

$$
A=\left[\begin{array}{cc}
\left(1-\pi_{1}\right) & \pi_{1} \\
0 & 1
\end{array}\right]
$$

Thus, over short horizons the process will look non-ergodic. 18 with this specification, it is straightforward to show that $\pi_{2}=\pi_{1}\left(2-\pi_{1}\right) .19$

Table 3 reports the results of estimating the model imposing this restriction. As the evidence indicates, incorporating the evolution of probabilities significantly improves the precision of estimation. The onestep ahead probabilities for all three instrument sets have point estimates between .25 and .3 and are significantly different than zero at the 908 confidence level. The two-month ahead probabilities are all significantly different than one and have point estimates greater than the one-month ahead probabilities. These estimates suggest that as the horizon increased, market participants thought it more likely that the Fed would change policy. Indeed, the test for the hypothesis that the two-month ahead probabilities were greater than the $\pi_{1}$ was rejected using the larger instrument set $A$. In addition, the over-identifying restrictions were not rejected for any case.

Interestingly, all three sets of information variables imply that the term premium was significantly greater than one. Thus, although the ex post returns on longer bonds were generally less than those obtained from rolling over short deposits, traders holding longer term bonds required a built-in

${ }^{18}$ This assumption is not overly restrictive, however, since by defining an additional state and treating state 2 as a transitional state, the process can be rendered ergodic. For the application in the text, we require only that the conditional process appear non-ergodic over the short two month ahead horizon.

${ }^{19}$ To see this, note that the transition matrix 2 months ahead is simply $A^{2}$. Reading the transition probability from state 1 today to state 2 in two months ahead gives $\pi_{2}$ in terms of $\pi_{1}$. 
term premium ex ante.

\section{The "Peso Problem" With Time-Varying Probabilities}

The estimation model above provides an informative account of the 'peso problem' in the interest rate process assuming the market assessed a constant probability to a change in Federal Reserve policy during the NBR period. It seems likely, however, that the market's anticipations of a policy shift changed over time during this period. For example, as interest rates continued to rise to record peaks in the summer to fall of 1981 , strong political pressures mounted for a change in Fed policy, therefore increasing its likelihood.

To investigate time-variation in the probabilities, we may estimate equations (3.2) and (3.3) but allowing the probabilities to depend upon the information variables, $z_{t}$. For this purpose, the one-month ahead probabilities were specified as functions of information according to, (7.1) $\pi=1 /\left(1+\delta^{\prime} z_{t}\right)^{2}$

This function is related to the Burr distribution as discussed in Maddala (1983). The two-month ahead probabilities were then restricted by the Markov restriction on the one-month ahead probabilities in eqn. (6.1).

Figure 1 depicts the one-month ahead probability estimated using the larger Information Set $A$ at weekly frequencies for the period from october 12 , 1979 to September $24,1982.20$ As the figure illustrates, the probabilities vary over time between a low near 48 such as during the spring of 1980 to a peak of 488 during the summer of 1981 as short rates reached historically high levels. Interestingly, the average levels of the probabilities are higher in

20 The behavior of the probabilities using the other two sets ( $B$ and $C$ ) were very similar. 
late 1981 into 1982, in anticipation of the ultimate abandonment of the NBR operating regime in the fall of 1982.

The time-varying and constant probability estimates may also be used to estimate the behavior of the "peso problem" effects, given as the second and third components on the right-hand side in eq. (3.3). Figure 2 plots these effects upon the ex post returns of three-month relative to rolling over onemonth deposits for both the constant probability estimates as reported in Table 3, and the time-varying probability estimates. As the figure illustrates, the peso problem effects are generally negative as expected. For both versions of the probabilities, the "peso problem" effects are quite variable and follow a similar pattern, although the time-varying probability estimate induces somewhat greater variation. Thus, the results suggest that the presence of "peso problem" effects during the NBR targeting period induce sizeable effects upon excess returns on longer term bonds even if there had been no variation in the market's beliefs that the Fed would change policy.

\section{Concluding Remarks}

This paper has investigated empirically the effects upon excess returns to longer term bonds from an anticipation by the financial market that the Federal Reserve would abandon its policy of targeting non-borrowed reserves during the 1979 to 1982 period. The evidence suggests that these anticipations significantly reduced the ex post returns on three month deposits relative to rolling over one month deposits. Also, the empirical estimates indicate that the market believed it more liekly that policy would change within two months than one month. Furthermore, when allowed to vary over time, these probabilities follow a pattern generally consistent with political pressures on the Federal Reserve to abandon the NBR targeting policy. 


\section{References}

COSSLETT, STEPHEN R. AND LUNG-FEI LEE, "Serial Correlation in Discrete Variable Models," Journal of Econometrics 27 (1985), 79-97.

CUMBY, ROBERT E., AND JOHN HUIZINGA, "Testing the Autocorrelation Structure of Disturbances in Least Squares and Instrumental Variables Models," Unpublished Manuscript, New York University (September 1988a).

Guide," New York University (September 1988b).

FAMA, EUGENE F., "The Information in the Term Structure," Journal of Financial Economics 13 (1984), 509-528.

FROOT, KENNETH, "New Hope for the Expectations Hypothesis of the Term Structure of Interest Rates," Unpublishied Manuscript, Massachusetts Institute of Technology (February 1988).

GOLDFELD, S.M., AND R.E. QUANDT, "A Markov Model of Switching Regressions," Journal of Econometrics 1 (1973): 3-16.

HAKKIO, CRAIG S., "The Term Structure of the Forward Premium," Journal of Monetary Economics 8 (1981a), 41-58.

Economic Review 22 (1981b), 663-678.

HAMILTON, JAMES D., "Rational-Expectations Econometric Analys is of Changes in Regimes: An Investigation of the Term Structure of Interest Rates," Journal of Economic Dynamics and Control 12 (1988), 385-423. , "Analysis of Time Series Subject to Changes in Regime," Unpublishied Working Paper, University of Virginia (January, 1989). HANSEN, LARS P., "Large Sample Properties of Generalized Method of Moments Estimators," Econometrica 10 (July 1982), 1029-1054. 
AND ROBERT J. HODRICK, "Forward Exchange Rates as Optimal

Predictors of the Future Spot Rates: An Econometric Analysis, "Journal of Political Economy 88 (1980), 829-853.

KRASKER, WILIIAM S., "The 'Peso Problem' in Testing the Efficiency of Forward Exchange Markets," Journal of Monetary Economics 6 (April 1980), 269-276.

LEWIS, KAREN K., "Was There a 'Peso Problem' in the U.S. Term Structure of Interest Rates: 1979 - 1982?" Salomon Brothers Working Paper Series, New York University (1988).

LIZONDO, JUAN S., "Foreign Exchange Futures Prices under Fixed Exchange Rates," Journal of International Economics 14 (February 1983), 69-84. MADDALA, G.S., Limited-Dependent and Qualitative Variables in Econometrics (Cambridge: Cambridge University Press, 1983).

MANKIW, N. GREGORY, "The Term Structure of Interest Rates Revisited," Brookings Papers on Economic Activity 1 (1986), 61-96.

NEFTCI, SALIH N., "Optimal Prediction of Cyclical Downturns," Journal of Economic Dynamics and Control 4 (1982), 225-241.

NEWEY, WHITNEY K., AND.KENNETH D. WEST, "A Simple, Positive Semi-Definite, Heteroskedasticity and Autocorrelation Consistent Covariance Matrix," Econometrica 55 (May 1987a), 703-708.

Method of Moments Estimation," International Economic Review 28 (October 1987b), 777-787.

ROGOFF, KENNETH S., "Essays on Expectations and Exchange Rate Volatility," Unpublished Ph.D. Dissertation, Massachusetts Institute of Technology, 1979. SHILLER, ROBERT, AND HUSTON MCCULLOUGH, "The Term Structure of Interest Rates," NBER Working Paper No. 2341 (August 1987). 
TABLE 1

SUMMARY STATISTICS FOR PROJECTION EQUATIONS

$$
\text { One Month Ahead: } y_{t}=\sum_{i=0}^{h} \alpha_{i j} z_{j t}+\varepsilon_{t, j}
$$

Two Months Ahead: $y_{t}=\sum_{i=0}^{h} \gamma_{i j} z_{i t}+v_{t, j}$, for $j=1,2$

\begin{tabular}{lrrr}
\hline Sample Period: & $\begin{array}{r}\text { Feb. } 1976 \\
-0 c t .1979\end{array}$ & $\begin{array}{r}\text { Oct. } 1979 \\
\text {-Sep. } 1982\end{array}$ & $\begin{array}{r}\text { Oct. } 1982 \\
\text {-May } 1986\end{array}$ \\
\hline & Instrument Set $\left(\mathrm{Z}_{1 \mathrm{t}}\right):$
\end{tabular}

A. One and Two Month Ahead Change Projection Equations

\begin{tabular}{|c|c|c|c|c|c|c|c|c|c|}
\hline \multicolumn{10}{|l|}{$1 \cdot y_{t}=\left(r_{t+4}-r_{t}\right)$} \\
\hline \multicolumn{10}{|l|}{ M.S.L. for } \\
\hline Ho: $\alpha_{i j}=0, \forall 1$ & .005 & .001 & .033 & .021 & .001 & .036 & .135 & .246 & .110 \\
\hline $\mathrm{R}^{2}$ & .062 & .052 & .030 & .120 & .112 & .113 & .093 & .044 & .161 \\
\hline \multicolumn{10}{|l|}{$\begin{array}{l}\text { M.S.L. for } \\
\text { Ho: } E\left(\varepsilon t^{c} t-3-q\right)\end{array}$} \\
\hline for $q-1, .6$ & .027 & .022 & .010 & .656 & .266 & .191 & .638 & .664 & .718 \\
\hline \multicolumn{10}{|l|}{ M.S.L. for } \\
\hline $\begin{array}{l}\text { Set A: }<.000 \\
\text { Set B: }<.000 \\
\text { Set } C:<.016\end{array}$ & & & & & & & & & \\
\hline \multicolumn{10}{|c|}{$2 \cdot y_{t}=\left(r_{t+8}-r_{t+4}\right)$} \\
\hline \multicolumn{10}{|l|}{ M.S.L. for } \\
\hline Ho: $\gamma_{i j}=0, \forall i$ & .156 & .144 & .065 & .005 & .002 & .003 & .286 & 239 & .080 \\
\hline $\mathrm{R}^{2}$ & .041 & .034 & .028 & .251 & .237 & .209 & .153 & .139 & .112 \\
\hline \multicolumn{10}{|c|}{ M.S.L. for } \\
\hline for $q=1, \ldots, 6$ & .345 & .370 & .017 & .761 & .672 & .643 & .821 & .814 & .760 \\
\hline \multicolumn{9}{|l|}{ M.S.L. for } & Ho: $\gamma_{i 1}=\gamma_{i 2}, \forall i$ \\
\hline $\begin{array}{l}\text { Set A: }<.000 \\
\text { Set B: }<.000 \\
\text { Set C: } \quad .002\end{array}$ & & & & & & & & & \\
\hline
\end{tabular}


TABLE 1 (CONTINUED)

SUMMARY STATISTICS FOR PROJECTION EQUATIONS

\begin{tabular}{rrrrr}
\hline Sample Period: & Feb. 1976 & Oct. 1979 & $0 c t$. \\
& -Oct. 1979 & - Sep. 1982 & - May 1986 & 1986 \\
\hline
\end{tabular}

Instrument $\operatorname{set}\left(Z_{i t}\right)$ :

Set $A$ Set $B$ set $C$ Set A set $B$ set $C$ set $A$ set $B$ Set $C$

B. One and Two Month Ahead Projection Equations

1. $y_{t}=\left(r_{t+4}-r_{t}\right)$

M.S.L. for

Ho: $\alpha_{i j}=0, \forall i$

$<.000<.000<.000$

$<.000<.000<.000$

$<.000<.000<.000$

R2

$.847 \quad .846 \quad .833$

$.914 \quad .911 \quad .488$

$.870 \quad .862 \quad .851$

M.S.L. for

Ho: $E\left(\varepsilon t^{\varepsilon} t-3-q\right)$

for $q-1, \ldots, 6$

$.744 \quad .711 \quad .685$

$\begin{array}{lll}.678 & .617 \quad .071\end{array}$

$.325 \quad .238$

.316

M.S.L. for

Ho: $\alpha_{i 1}-\alpha_{i 2}, \forall i$

Set $A:<.000$

Set B: <. 000

Set C: $<.000$

2. $y_{t}=\left(r_{t+8}-r_{t+4}\right)$

M.S.L. for

Ho: $\gamma_{i j}-0, \forall i$

$\mathrm{R}^{2}$

$\begin{array}{rrrrrrrrr}<.000 & <.000 & <.000 & <.000 & <.000 & <.000 & <.000 & <.000 & <.000 \\ .808 & .807 & .801 & .503 & .497 & .153 & .827 & .816 & .806\end{array}$

M.S.L. for

Ho: $E\left(\varepsilon t^{\varepsilon} t-3-q\right)-0$

for $q=1, \ldots, 6$

M.S.L. for

Ho: $\gamma_{i 1}-\gamma_{i 2}, \forall i$

Set $A:<.000$

Set B: $<.000$

Set $C:<.000$

Instrument Set $A$ is a constant, the one-month deposit rates on the Euro DM, Euro Sterling and Euro Guilder each minus the Eurodollar rate, and the spreads between the threemonth and one-month EuroDM, Euro Sterling and Euro Guilder.

Instrument Set $B$ is the same as Instument Set A but excluding the Euro Guflder variables.

Instrument set $C$ is the same as Instrument Set $A$ but excluding the spreads between the three month and one month Eurocurrency rates. 
PARAMETER ESTIMATES AND TESTS OF THE "PESO PROBLEM"

$$
\begin{aligned}
& \text { "Peso Problem" Equation: } \\
& \left(R_{t}-(1 / 3) \sum_{s=0}^{2} r_{t+4 s}\right)-\theta+\pi_{1}(1 / 3) \sum_{i=0}^{H}\left(\alpha_{i 2}-\alpha_{i 1}\right) z_{i t}+\pi_{2}(1 / 3) \sum_{i=0}^{H}\left(\gamma_{i 2}-\gamma_{i 1}\right) z_{i t}+e_{t}
\end{aligned}
$$

\begin{tabular}{lccc}
\hline & & Instrument Set $\left(\mathrm{z}_{\text {it }}\right)$ \\
& Set A & Set B & Set C \\
\hline$\pi_{1}$ & -1.96 & -2.57 & -1.38 \\
$\pi_{2}$ & $(1.12)$ & $(1.98)$ & $(1.70)$ \\
& $1.75^{\mathrm{a}}$ & $1.97^{\mathrm{a}}$ & 1.37 \\
& $(.53)$ & $(.81)$ & $(.71)$ \\
& -.25 & -.89 & .06 \\
M.S.L. for & $(.97)$ & $(2.00)$ & $(1.67)$ \\
Ho: $\pi_{1}-\pi_{2}-0$ & $<.000$ & & $<.000$ \\
M.S.L. for & & $<.000$ & .252 \\
Ho: $\pi_{1}=\pi_{2}$ & .024 & & \\
M.S.L. for & & .101 & .468 \\
$\begin{array}{c}\text { Test of } \\
\text { Restrictions }\end{array}$ & .588 & & \\
\hline
\end{tabular}

Asymptotic standard errors are in parenthesis.

andicates significantly different than zero at the 958 confidence level. Instrument Sets $A$ to $C$ are as defined in Table 1. 
TABLE 3

PARAMETER ESTIMATES AND TESTS OF THE "PESO PROBLEM"

WITH PROBABILITIES CONSTRAINED BY MARKOV PROCESS

"Peso Problem" Equation:

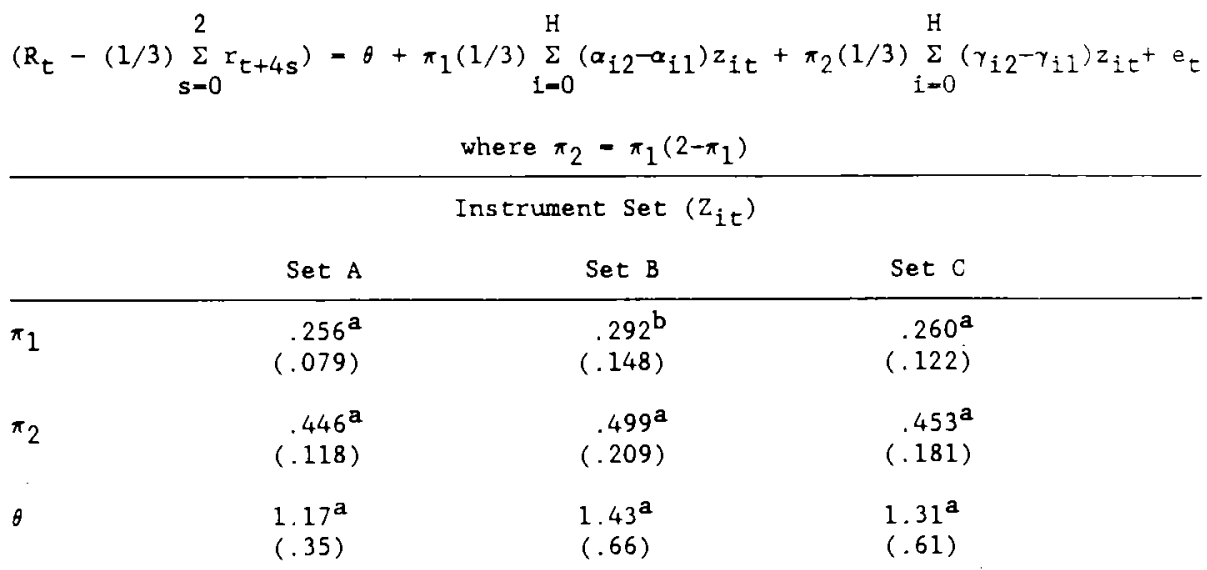

M.S.L. for

Ho: $\pi_{1}=\hat{\pi}_{2}$

.016

.162

.116

M.S.L. for

Test of

Restrictions

.526

.349

.418

Asymptotic standard errors are in parenthesis.

${ }^{a}$ Indicates significantly different than zero at the 958 confidence 1 evel.

bIndicates significantly different than zero at the 90 s confidence 1 evel.

Instrument Sets $A$ to $C$ are as defined in Table 1 . 


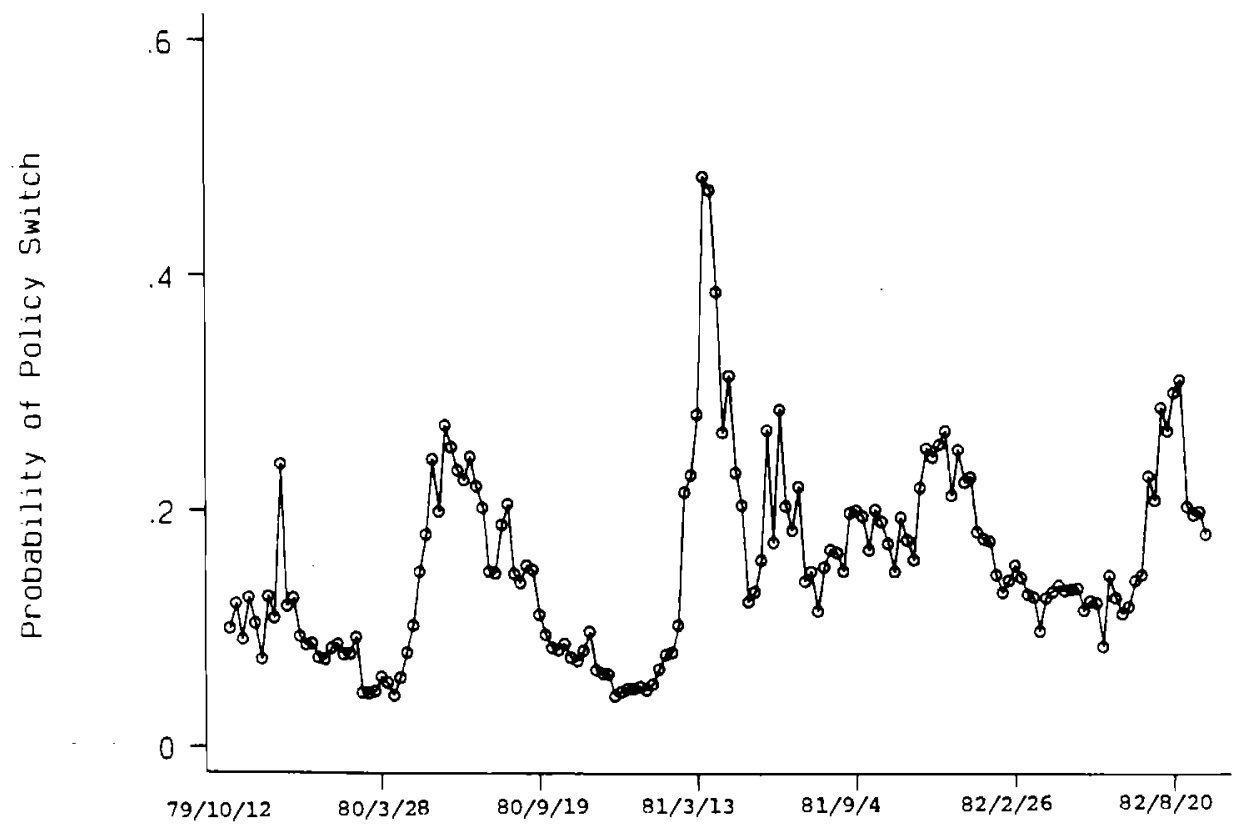

Figure 1 
- Peso Problem/Constant Prob a Peso Problem/Varying Prob

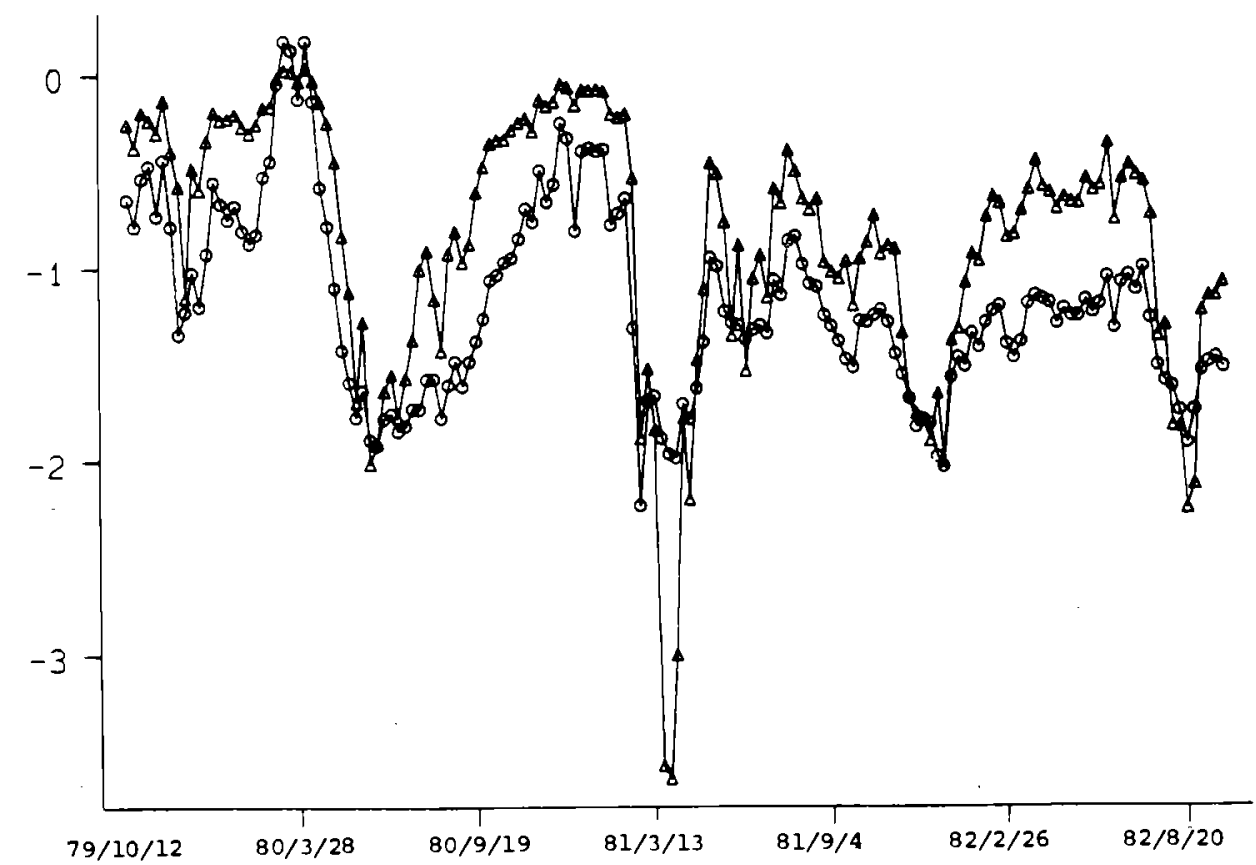

Figure 2: Peso Problem Effects 